\title{
Clinical and Molecular Features of POLG-Related Mitochondrial Disease
}

\author{
Jeffrey D. Stumpf ${ }^{1}$, Russell P. Saneto ${ }^{2}$, and William C. Copeland ${ }^{1}$ \\ ${ }^{1}$ Laboratory of Molecular Genetics, National Institute of Environmental Health Sciences, National \\ Institutes of Health, Research Triangle Park, North Carolina 27709 \\ ${ }^{2}$ Division of Pediatric Neurology, Seattle Children's Hospital/University of Washington, Seattle, \\ Washington 98105 \\ Correspondence: copelan1@niehs.nih.gov
}

\begin{abstract}
The inability to replicate mitochondrial genomes (mtDNA) by the mitochondrial DNA polymerase ( $\mathrm{pol} \gamma$ ) leads to a subset of mitochondrial diseases. Many mutations in POLG, the gene that encodes pol $\gamma$, have been associated with mitochondrial diseases such as myocerebrohepatopathy spectrum (MCHS) disorders, Alpers-Huttenlocher syndrome, myoclonic epilepsy myopathy sensory ataxia (MEMSA), ataxia neuropathy spectrum (ANS), and progressive external ophthalmoplegia (PEO). This chapter explores five important topics in POLG-related disease: (1) clinical symptoms that identify and distinguish POLGrelated diseases, (2) molecular characterization of defects in polymerase activity by $P O L G$ disease variants, (3) the importance of holoenzyme formation in disease presentation, (4) the role of pol $\gamma$ exonuclease activity and mutagenesis in disease and aging, and (5) novel approaches to therapy and avoidance of toxicity based on primary research in pol $\gamma$ replication.
\end{abstract}

W hile many polymerases are responsible for replicating billions of nucleotides in the nucleus, DNA polymerase $\gamma$ replicates thousands of copies of the 16-kilobase mitochondrial genome (mtDNA) in each human cell. The holoenzyme of DNA polymerase $\gamma(\operatorname{pol} \gamma)$ consists of a catalytic subunit (encoded by $P O L G$ at chromosomal locus 15q25) and a dimeric form of its accessory subunit (encoded by POLG2 at chromosomal locus 17q24.1) (Longley et al. 1998b; Lim et al. 1999). MtDNA encodes 13 proteins that are essential for the electron transport chain that provides most of the ATP in the cell. Therefore, mtDNA replication is essential for life as demonstrated by the embryonic lethality of POLG knockout mice (Hance et al. 2005). Studies over the last decade have identified over 200 mutations in $P O L G$ that are associated with certain mitochondrial diseases (http://tools.niehs. nih.gov/polg/) (Longley et al. 2005: Copeland 2008; Longley et al. 2010; Walter et al. 2010; Stumpf and Copeland 2011; Tang et al. 2011). POLG-related disorders are currently defined by at least five major phenotypes of neurodegenerative disease that include: (1) Alpers-Huttenlocher syndrome (AHS), (2) childhood myocerebrohepatopathy spectrum (MCHS), (3) myoclonic epilepsy myopathy sensory ataxia (MEMSA),

Editors: Douglas C. Wallace and Richard J. Youle

Additional Perspectives on Mitochondria available at www.cshperspectives.org

Copyright (C) 2013 Cold Spring Harbor Laboratory Press; all rights reserved; doi: 10.1101/cshperspect.a011395

Cite this article as Cold Spring Harb Perspect Biol 2013;5:a011395 
(4) the ataxia neuropathy spectrum (ANS), and (5) progressive external ophthalmoplegia (PEO) with or without sensory ataxic neuropathy and dysarthria (SANDO) (Wong et al. 2008; Cohen et al. 2010; Saneto and Naviaux 2010; Saneto et al. 2010). These diseases associate with mutations that have been shown to decrease the activity of the polymerase, the fidelity of replication, and the formation of the holoenzyme. This work reviews the important conclusions regarding POLG-related diseases and discusses some strategies for disease treatment options.

\section{CLINICAL SYMPTOMS THAT IDENTIFY AND DISTINGUISH POLG-RELATED DISEASES}

The clinical identification of mitochondrial diseases associated with POLG mutations is difficult because $P O L G$-related diseases evolve over time and have an overlapping range of symptoms with multiple organ system involvement and with different degrees of severity and timing of onset. However, several important clues to the diagnosis include the tempo of disease progression, the presenting organ system, the combination of symptoms (but not necessarily the sequence of presentation or severity of organ involvement), and increasing involvement of neurological signs and symptoms during illness (especially viral infections producing fevers, or other physiological stressors) (Nguyen et al. 2006; Cohen et al. 2010). While no single test identifies $P O L G$-related diseases, proper diagnosis depends on the age of presentation and associated biochemical and neuroimaging findings. By definition, $P O L G$ mutations are necessary for $P O L G$-related disease, and identification of mutations known to facilitate disease (discussed later) is necessary for use as a diagnostic tool. The correct combination of laboratory testing and clinical observations (Table 1) identifies specific diseases and allows the monitoring of the course of the disease. Although the broad clinical expression of POLG-related diseases can make diagnoses difficult, there are phenotypic similarities and ages of onset that reflect distinct syndromes (Table 2) (Wong et al. 2008; Saneto and Naviaux 2010).
Table 1. Evaluation of patients with POLG disease ${ }^{a}$

\begin{tabular}{|c|c|}
\hline Organ system & Test \\
\hline \multirow[t]{5}{*}{ CNS } & $\begin{array}{l}\text { EEG (with possible Video-EEG re- } \\
\text { quired for subtle seizures) }\end{array}$ \\
\hline & $\begin{array}{l}\text { MRI of the brain (T1/T2/FLAIR/ } \\
\text { Diffusion) }\end{array}$ \\
\hline & MRS of the brain (TE 30 and either \\
\hline & TE $130(1.5 \mathrm{~T})$ or TE $288(3.0 \mathrm{~T})$ \\
\hline & Neurological examination \\
\hline \multirow[t]{2}{*}{ Vision } & $\begin{array}{l}\text { Formal visual exam (including eye } \\
\text { movements) }\end{array}$ \\
\hline & $\begin{array}{l}\text { Electroretinogram and visual evoked } \\
\text { potential if clinically indicated }\end{array}$ \\
\hline Hearing & $\begin{array}{l}\text { Brain stem auditory evoked poten- } \\
\text { tials if clinically indicated }\end{array}$ \\
\hline Cardiac & $\begin{array}{l}\text { EKG (may also consider ECHO if } \\
\text { clinically indicated) }\end{array}$ \\
\hline \multirow[t]{4}{*}{ Liver } & $\begin{array}{l}\text { Liver biopsy (for pathological eval- } \\
\text { uation and mitochondrial DNA } \\
\text { content) }\end{array}$ \\
\hline & Liver enzyme and function studies \\
\hline & $\begin{array}{l}\text { (ALT, AST, GGT, fasting glucose, } \\
\text { albumin, prothrombin time and }\end{array}$ \\
\hline & $\begin{array}{l}\text { INR, ammonia, bilirubin, cho- } \\
\text { lesterol) }\end{array}$ \\
\hline \multirow[t]{2}{*}{ Gastrointestinal } & $\begin{array}{l}\text { Gastric emptying and bowel mo- } \\
\text { tility if clinically indicated }\end{array}$ \\
\hline & $\begin{array}{l}\text { Swallowing study if clinically in- } \\
\text { dicated }\end{array}$ \\
\hline \multirow[t]{2}{*}{ Respiratory } & Pulmonary function testing \\
\hline & $\begin{array}{l}\text { Sleep polysomnography to evaluate } \\
\text { hypercapnia during sleep }\end{array}$ \\
\hline Systemic & $\begin{array}{l}\text { Blood acylcarnitines, total and free } \\
\text { carnitine, plasma amino acids }\end{array}$ \\
\hline
\end{tabular}

${ }^{a}$ Adapted from Haas et al. $(2007,2008)$ and Cohen and Naviaux (2010).

Even with a multitude of tests for mitochondrial disease, there are many examples where the results may lead to a difficult or improper diagnosis. For instance, extracting muscle to assay electron transport chain complex activity is useful in identifying mitochondrial cytopathy, but not necessarily POLG-related diseases (Gonzalez-Vioque et al. 2006; de Vries et al. 2007; Saneto et al. 2010). In addition, the use of mitochondrial DNA (mtDNA) depletion assays can be misleading for two reasons: normal mtDNAvalues would not exclude POLG disease, especially early in the course of the disease, and 
Table 2. Major clinical syndromes associated with POLG mutations ${ }^{a}$

\begin{tabular}{|c|c|c|}
\hline Age of onset & Syndrome & References \\
\hline Neonatal/infancy & Myocerebrohepatopathy spectrum (MCHS) & $\begin{array}{l}\text { Ferrari et al. 2005; de Vries et al. } \\
\quad 2007\end{array}$ \\
\hline Infancy/childhood & Alpers-Huttenlocher syndrome (AHS) & Naviaux and Nguyen 2004 \\
\hline \multirow{3}{*}{$\begin{array}{l}\text { Adolescent/young } \\
\text { adult }\end{array}$} & Ataxia neuropathy spectrum (ANS) ${ }^{\mathrm{b}}$ & Hakonen et al. 2005 \\
\hline & $\begin{array}{l}\text { Myoclonus, epilepsy, myopathy, sensory ataxia } \\
\text { (MEMSA) }\end{array}$ & Van Goethem et al. 2004 \\
\hline & Progressive external ophthalmoplegia $(\mathrm{PEO})^{\mathrm{c}, \mathrm{d}}$ & Van Goethem et al. 2001 \\
\hline \multicolumn{3}{|c|}{$\begin{array}{l}\text { a Table data adapted from Saneto and Naviaux (2010). } \\
\text { bANS has also been labeled as mitochondrial recessive ataxia syndrome (MIRAS), sensory ataxic neuropathy with dysarthria } \\
\text { d ophthalmoplegia (SANDO), and spino-cerebellar ataxia epilepsy syndrome (SCAE) (Tzoulis et al. 2006). } \\
\text { cPEO is labeled as PEO+ when associated with additional symptoms that may include peripheral neuropathy, ataxia, } \\
\text { earing loss, depression, premature menopause, hypogonadism, Parkinsonism, cataracts, or GI dysmotility. } \\
{ }^{d} \text { Dominant and recessive mutations in POLG have been associated with PEO. }\end{array}$} \\
\hline
\end{tabular}

mtDNA copy number is variable among different tissues (Dimmock et al. 2010). Finally, Van Goetham et al. (2003b) described several patients with mitochondrial neurogastrointestinal encephalopathy (MNGIE)-like syndrome, but without the cardinal finding of leukoencephalopathy as described in true MNGIE (Hirano et al. 1994). The MNGIE-like patients do not have deficiency in thymidine phosphorylase activity and would not respond to allogenic stem cell transplantation. Thus, proper treatment may be delayed or incorrectly given. To assist in the proper diagnosis of POLG related disease, the following section lists clinical features of the five most characterized POLG-related disorders.

\section{Myocerebrohepatopathy Spectrum (MCHS) Disorders}

MCHS disorders present in the first two to three years of life and result in early death. The clinical features of MCHS disorders include encephalopathy/developmental delay, liver dysfunction, myopathy, and hypotonia. Like other mitochondrial disorders, gastrointestinal (GI) dysmotility and failure to thrive occurs in MCHS disorders, albeit at earlier ages. Seizures may occur in these patients, but are not a necessary or dominant feature. Liver involvement can be the most dramatic feature with early failure leading to death. For instance, one compound heterozy- gous MCHS patient with G848S and R1096C mutations in POLG presented at 5 months of age with encephalopathy, hypotonia, and liver failure (RP Saneto, unpubl.). The biopsy showed that the liver pathology was distinct from what is commonly seen in another infantile onset POLG-related disease, Alpers-Huttenlocher (Nguyen et al. 2006). This patient died at 11 months of age because of liver failure.

\section{Alpers-Huttenlocher Syndrome (AHS)}

Also referred to as Alpers syndrome, AHS presents most frequently during infancy (similar to MCHS) and is fatal. Epilepsy is usually the predominant feature in AHS with an early predilection of epileptiform discharges over the occipital region of the brain, and generalized discharges as the disease progresses (Tulinius and Hagne 1991; Engelsen et al. 2008; Wolf et al. 2009; Saneto et al. 2010). Early seizures have the semiology of occipital lobe seizures with vomiting, headache, and myoclonus. Most patients have multiple episodes of epilepsia partialis continua and/or convulsive status epilepticus. Early in the course of epilepsy, seizures are often controlled with conventional medications. However, as the disease progresses, the seizures become increasingly resistant to valproic acid and other medications that trigger liver failure (Bicknese et al. 1992; Engelsen et al. 2008; Uusimaa et al. 2008; Wolf et al. 2009; Saneto et al. 2010). Even without 
valproic acid dosing, liver failure occurs in AHS patients, and liver pathology cannot distinguish the samples that were treated with valproic acid (Harding 1990). Characteristic features of liver pathology in AHS require at least three of the following histological findings: (1) microvesicular steatosis, (2) bile ductular proliferation, (3) hepatocyte dropout, (4) bridging fibrosis or cirrhosis, (5) collapse of liver cell plates, (6) parenchymal disarray or disorganization of normal lobular architecture, (7) regenerative nodules, and (8) oncocytic change in scattered hepatocytes not affected by steatosis (Nguyen et al. 2006).

In addition to liver pathology, other common clinical features of AHS include headaches that are migrainous in nature, cortical blindness usually in fully developed AHS, and myoclonus often in the later phases of the disease (Nguyen et al. 2006; Cohen et al. 2010). Myoclonus may become so rapid that they become indistinguishable from myoclonic seizures. The onset and tempo of cognitive impairment is variable and often triggered by infectious illness.

\section{Myoclonic Epilepsy Myopathy Sensory} Ataxia (MEMSA)

MEMSA has the dominant features of epilepsy, myopathy, and ataxia, but without ophthalmoplegia. A subclinical sensory polyneuropathy leading to ataxia is usually the first sign of the disease. Usually seen later in the disease course, myoclonic seizures are often focal, frequently involving an arm, and can become generalized over time and comorbid with a progressive encephalopathy. Two features distinguish MEMSA from other similar diseases. First, the lack of ophthalmoplegia and prominence of myopathy sets these patients apart from other POLG syndromes. Second, histochemical assays of the muscle reveal the absence of ragged-red fibers distinguishing this syndrome from myoclonus epilepsy with raggedred fibers (Van Goethem et al. 2003b).

\section{Ataxia Neuropathy Spectrum (ANS)}

ANS presents from early adolescence to the late third decade, and may be the most difficult to diagnose. While the predominant features of
ANS are neuropathy and ataxia without myopathy, patients may also express progressive external ophthalmoplegia (Van Goethem et al. 2004). A wide variety of symptoms have been associated with ANS, including mild cognitive impairment, involuntary movements, psychiatric symptoms, myoclonus, blindness, hearing loss, and liver involvement (Van Goethem et al. 2004; Hakonen et al. 2005; Winterthun et al. 2005; Tzoulis et al. 2006). Commonly, ANS patients also present with white matter brain lesions as shown by MRI (Van Goethem et al. 2004).

Progressive External Ophthalmoplegia (PEO)

$\mathrm{PEO}$ (or $\mathrm{PEO}+$, which indicates multiple organ involvement) is an adult onset disorder that occurs with dominant or recessive POLG mutations (Van Goethem et al. 2001; Lamantea et al. 2002). Although the major clinical finding is a progressive weakness of the extraocular eye muscles resulting in ptosis and loss of eye movements in the horizontal and vertical directions (Van Goethem et al. 2001), a generalized myopathy is present in most patients. Other symptoms of $\mathrm{PEO}+$ include sensory ataxia, neuropathy, dysarthria, myopathy, and restless leg syndrome (Fadic et al. 1997; Van Goethem et al. 2001; Milone et al. 2008; Aitken et al. 2009; Blok et al. 2009). Cosegregating with PEO families are features of Parkinsonism (Luoma et al. 2004), premature ovarian failure, sensory ataxia (Pagnamenta et al. 2006), and cataracts (Luoma et al. 2004; Blok et al. 2009).

\section{MOLECULAR CHARACTERIZATION OF DEFECTS IN POLYMERASE ACTIVITY BY POLG DISEASE VARIANTS}

Identification of $P O L G$ mutations is the unifying characteristic of POLG-related disease. Ever since the landmark paper by Van Goethem et al. (2001) identified the cosegregation of PEO with POLG mutations, searches for other diseaseassociated mutations have resulted in an exponentially increasing number of mutations found in disease patients (http://tools.niehs. nih.gov/polg). Most mutations are found in compound heterozygotes containing multiple 
mutations in cis and in trans. However, some mutations do not affect enzyme function in known biochemical assays or in yeast model systems. The consideration that as few as 43 mutations have been described in multiple publications describing nonrelated families raises doubts as to whether all of the hundreds of mutations that have only shown to cosegregate with disease in a single publication are in fact causative of disease. In fact, at least 32 mutations have been identified only in cis with another POLG mutation, and the relative contribution of each mutation on the same chromosome is difficult to interpret without further analysis. Although it is useful to have a comprehensive record of $P O L G$-associated mutations, it is imperative to characterize mutations that are likely to cause disease by recording adequate genotypic family histories, determining mitochondrial dysfunction in model systems, or measuring deficiency of enzymatic activity (summarized in Table 3).

The catalytic subunit of pol $\gamma$ is a $140-\mathrm{kD}$ protein containing DNA polymerase, $3^{\prime}-5^{\prime}$ exonuclease and $5^{\prime}$ dRP lyase activities (Gray and Wong 1992; Longley et al. 1998a,b). Defects in DNA polymerase activity have been detected in many POLG mutations studied, suggesting that the reduced polymerase activity facilitates disease progression. Although $5^{\prime} \mathrm{dRP}$ lyase is an important step in mtDNA base excision repair, the critical residues for lyase activity are unknown, making it difficult to ascertain the importance of lyase activity in maintenance of mitochondrial genomes.

Mutations in POLG were first identified in 2001 as a disease locus for PEO (Van Goethem et al.2001). With the exception of one mutation, all dominant POLG mutations responsible for developing PEO are mapped to the polymerase domain of pol $\gamma$. Three of the substitutions, H932Y, R943H, and Y955C, change side chains that interact directly with the incoming dNTP (Graziewicz et al. 2004; Stumpf et al. 2010). These enzymes retain less than 1\% of the wildtype polymerase activity and display a severe decrease in processivity (Graziewicz et al. 2004), characteristics that likely cause the severe clinical presentation in $\mathrm{R} 943 \mathrm{H}$ and Y955C heterozy- gotes (Graziewicz et al. 2004). In addition, in vitro assays showed that the Y955C substitution also increases nucleotide misinsertion errors 10 - to 100-fold in the absence of exonucleolytic proofreading (Ponamarev et al. 2002). In vivo evidence in yeast showed that alteration of the conserved tyrosine in the yeast mitochondrial polymerase gene, mip 1, enhanced mtDNA damage, increased mutagenesis, and resulted in cells with dysfunctional mitochondria (Baruffini et al. 2006; Stuart et al. 2006). Similar to dominance seen in human patients, heterozygous yeast that alter the conserved tyrosine show a dominant increase in mitochondrial dysfunction, suggesting that the mutant enzymes compete with the wild-type polymerases for binding at the replication fork (Stuart et al. 2006). Additionally, a mouse transgenic model with the Y955C POLG allele targeted to the heart resulted in cardiomyopathy, loss of mtDNA, and enlarged hearts (Lewis et al. 2007). These models strongly suggest that large reductions in pol $\gamma$ polymerase activity are sufficient to cause mitochondrial dysfunction that is central to POLGrelated disease.

Other POLG disease-associated mutations have been assayed for polymerase activity to determine the potential to cause disease. Polymerase active site mutations G923D and A957S are found in PEO patients and have been shown to exhibit $21 \%$ and $23 \%$ polymerase activity, respectively (Graziewicz et al. 2004). Analysis of a cluster of Alpers mutations in the thumb domain has shown a striking correlation with the severity of the defect and the degree of conservation of amino acid sequences among various eukaryotes (Kasiviswanathan et al. 2009). Mutations in the most conserved sites represented by G848S, T851A, R852C, and R853Q exhibited less than 1\% WTenzyme activity (Kasiviswanathan et al. 2009). Mutations in codons for less conserved amino acids (Gln879 and Thr885) resulted in only moderate reduction in activity (Kasiviswanathan et al. 2009). Haplotype analysis of the Finnish population demonstrates a carrier frequency of 1:125 for a common polymerase domain mutation, W748S (Hakonen et al. 2005). It has been shown that the W748S mutation caused the polymerase to have a low 


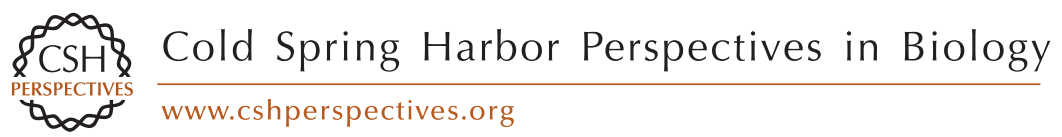

Table 3. Genetic and biochemical evidence for POLG variants causing disease

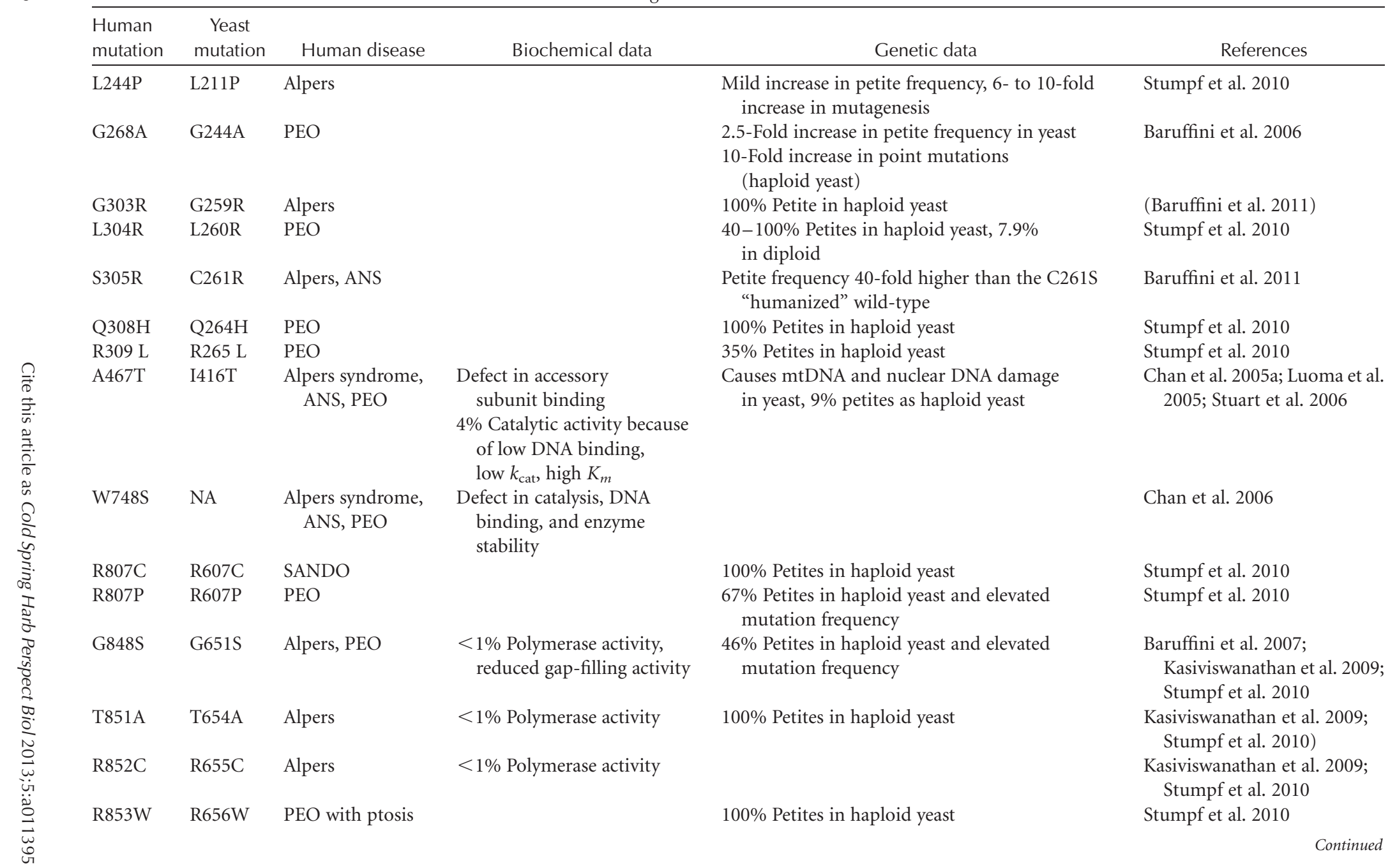


$\int_{\text {PERSPECTIVES }}^{\infty} \frac{\mathrm{CSH}}{\text { www cshperspectives org }}$

Table 3. Continued

\begin{tabular}{|c|c|c|c|c|c|}
\hline $\begin{array}{l}\text { Human } \\
\text { mutation }\end{array}$ & $\begin{array}{c}\text { Yeast } \\
\text { mutation }\end{array}$ & Human disease & Biochemical data & Genetic data & References \\
\hline R853Q & R656Q & Alpers & $\begin{array}{l}<1 \% \text { Polymerase } \\
\text { activity }\end{array}$ & $100 \%$ Petites in haploid yeast & $\begin{array}{l}\text { Kasiviswanathan et al. 2009; } \\
\text { Stumpf et al. } 2010\end{array}$ \\
\hline N864S & N667S & $\mathrm{PEO}$ & & $100 \%$ Petites in haploid yeast & Stumpf et al. 2010 \\
\hline E873X & E676 & Alpers syndrome & & $\begin{array}{l}\text { Stop codon leads to nonsense-mediated } \\
\text { decay of message }\end{array}$ & Chan et al. 2005b \\
\hline Q879H & NA & Alpers & $\begin{array}{l}50 \% \text { Polymerase } \\
\text { activity }\end{array}$ & & Kasiviswanathan et al. 2009 \\
\hline T885S & $\mathrm{NA}$ & Alpers & $\begin{array}{l}\text { 70\% Polymerase } \\
\text { activity }\end{array}$ & & Kasiviswanathan et al. 2009 \\
\hline G888S & G691S & Alpers & & $\begin{array}{l}\text { Mild increase in petite frequency and } \\
\text { mutagenesis }\end{array}$ & Stumpf et al. 2010 \\
\hline A889T & $\mathrm{A} 692 \mathrm{~T}$ & PEO & $\begin{array}{l}\text { Reduced gap-filling } \\
\text { activity }\end{array}$ & $17 \%$ Petite frequency in haploid yeast & Stumpf et al. 2010 \\
\hline G923D & G725D & PEO & $\begin{array}{l}21 \% \text { Polymerase } \\
\text { activity }\end{array}$ & $\begin{array}{l}100 \% \text { Petites in haploid yeast, only } 7.6 \% \\
\text { in diploid, dominant in humans }\end{array}$ & $\begin{array}{l}\text { Graziewicz et al. 2004; Stuart } \\
\text { et al. 2006; Stumpf et al. } 2010\end{array}$ \\
\hline D930N & $\mathrm{D} 732 \mathrm{~N}$ & Alpers & & $100 \%$ Petites in haploid yeast & Baruffini et al. 2011 \\
\hline R943H & $\mathrm{R} 745 \mathrm{H}$ & PEO & $\begin{array}{l}0.2 \% \text { Polymerase } \\
\text { activity because of } \\
\text { high } K_{m}(\mathrm{dNTP}) \text { and } \\
\text { lower } k_{\text {cat }}\end{array}$ & $\begin{array}{l}100 \% \text { Petites in haploid yeast, } 37 \% \text { in diploid } \\
\text { yeast, loss of mtDNA in yeast, dominant } \\
\text { in humans }\end{array}$ & $\begin{array}{l}\text { Graziewicz et al. 2004; Stuart } \\
\text { et al. 2006; Stumpf et al. } \\
2010\end{array}$ \\
\hline K947R & K749R & PEO & & $100 \%$ Petites in haploid yeast & Baruffini et al. 2011 \\
\hline Y955C & Y757C & $\begin{array}{l}\text { PEO, } \\
\text { Parkinsonism }\end{array}$ & $\begin{array}{l}0.03 \% \text { Polymerase } \\
\text { catalytic activity, } \\
\text { mutator polymerase }\end{array}$ & $\begin{array}{l}\text { Loss of mtDNA in transgenic mice, oxidative } \\
\text { stress, cardiomyopathy, high petite frequency } \\
\text { in yeast ( } 100 \% \text { in haploid, } 80 \% \text { in diploid), } \\
\text { dominant in humans }\end{array}$ & $\begin{array}{l}\text { Ponamarev et al. 2002; } \\
\text { Graziewicz et al. 2004; } \\
\text { Baruffini et al. 2006; Stuart } \\
\text { et al. } 2006\end{array}$ \\
\hline A957S & A759S & PEO & $23 \%$ Polymerase activity & $\begin{array}{l}35 \% \text { Petites in haploid yeast, only } 2.5 \% \text { in } \\
\text { diploid, dominant in humans }\end{array}$ & $\begin{array}{l}\text { Graziewicz et al. 2004; Stuart } \\
\text { et al. 2006; Stumpf et al. } \\
2010\end{array}$ \\
\hline A957P & A759P & Alpers & & $100 \%$ Petites in haploid yeast & Stumpf et al. 2010 \\
\hline
\end{tabular}




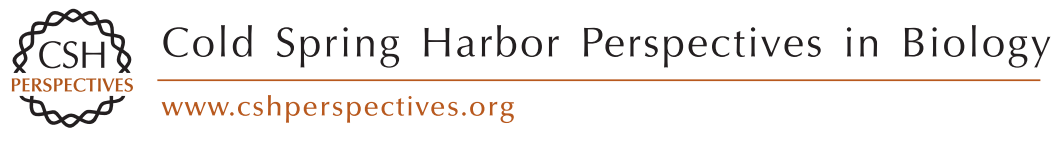

\begin{tabular}{|c|c|c|c|c|c|}
\hline $\begin{array}{l}\text { Human } \\
\text { mutation }\end{array}$ & $\begin{array}{c}\text { Yeast } \\
\text { mutation }\end{array}$ & Human disease & Biochemical data & Genetic data & References \\
\hline $\mathrm{R} 964 \mathrm{C}$ & NA & NRTI toxicity & $\begin{array}{l}\text { Reduced catalytic activity, } \\
\text { low } k_{\text {cat }}\end{array}$ & $\begin{array}{l}\text { Two- to threefold increase in petite } \\
\text { frequency upon exposure to stavudine in } \\
\text { haploid yeast }\end{array}$ & $\begin{array}{l}\text { Bailey et al. 2009a; Baruffini } \\
\text { and Lodi } 2010\end{array}$ \\
\hline G1051R & G807R & PEO, ataxia & $\begin{array}{l}\text { Slightly reduced gap- } \\
\text { filling activity }\end{array}$ & Mild increase of petites in haploid yeast & Stumpf et al. 2010 \\
\hline P1073 L & P829 L & Alpers & & 35 -Fold increase in petites in haploid yeast & Baruffini et al. 2011 \\
\hline G1076V & G832V & PEO & & $100 \%$ Petites in haploid yeast & Stumpf et al. 2010 \\
\hline R1096C & $\mathrm{R} 853 \mathrm{C}$ & PEO, Alpers & & $100 \%$ Petites in haploid yeast & Stumpf et al. 2010 \\
\hline $\mathrm{R} 1096 \mathrm{H}$ & $\mathrm{R} 853 \mathrm{H}$ & Alpers & & $100 \%$ Petites in haploid yeast & Stumpf et al. 2010 \\
\hline S1104C & S861C & PEO & & $100 \%$ Petites in haploid yeast & Stumpf et al. 2010 \\
\hline V1106I & V863I & PEO & & $100 \%$ Petites in haploid yeast & Stumpf et al. 2010 \\
\hline E1143G & E900G & $\begin{array}{l}\text { Polymorphism in } \\
4 \% \text { in population }\end{array}$ & $\begin{array}{l}\text { 1.4-Fold more active } \\
\text { than WT }\end{array}$ & $\begin{array}{l}\text { Temperature-sensitive mutant in yeast, high } \\
\text { petite frequency at } 36^{\circ} \mathrm{C}\end{array}$ & $\begin{array}{l}\text { Chan et al. 2006; Baruffini } \\
\text { et al. } 2007\end{array}$ \\
\hline $\mathrm{D} 1184 \mathrm{~N}$ & D941N & PEO & & $\begin{array}{l}33 \% \text { Increase in petites in haploid yeast and } \\
\text { mild mutagenesis }\end{array}$ & Stumpf et al. 2010 \\
\hline
\end{tabular}

NA, not applicable (because there is no homolog in yeast); ANS, ataxia neuropathy syndromes. 
catalytic activity and a severe DNA-binding defect (Chan et al. 2006). The W748S mutation is often found in combination with E1143G in ataxia patients (Hakonen et al. 2005; Winterthun et al. 2005) and was originally identified as an SNP in $4 \%$ of the general population (Di Fonzo et al. 2003; Van Goethem et al. 2004). However, biochemical evidence shows that the E1143G substitution partially reduces the deleterious effects of the W748S mutation, suggesting that E1143G may modulate the effects of disease mutations in POLG (Chan et al. 2006).

Yeast has been a useful model system to determine the functionality of $P O L G$ mutants by utilizing changes in residues that are in conserved stretches of amino acids (Baruffini et al. 2006, 2007, 2011; Stuart et al. 2006; Stumpf et al. 2010). Most of the mutations in conserved regions are in the polymerase domain, and many are completely unable to retain mitochondrial function because of disruption of mtDNA replication. These include PEO/SANDO-associated mutations R807C, R807P, R853W, N864S, G923D, H932Y, K947R, G1076V, R1096C, S1104C, and V1106I, and Alpers-associated mutations G848S, T851A, R853Q, D930N, A957P, P1073A, and R1096H (Stuart et al. 2006; Stumpf et al. 2010; Baruffini et al. 2011). By measuring a base substitution in mtDNA that confers erythromycin resistance, it was shown that mtDNA mutant frequency is increased by some disease-associated mutations (Baruffini et al. 2006, 2007, 2011; Stumpf et al. 2010). However, biochemical evidence of several mutants showed that the incorporation of an incorrect nucleotide is not more kinetically favorable (Kasiviswanathan et al. 2009; Szczepanowska and Foury 2010). Therefore, it is still unclear what causes the increase in mutagenesis in these mutant strains. Finally, information from the yeast studies allowed the comparison of multiple substitutions of the same residue that were associated with different diseases (Stumpf et al. 2010). The mutations associated with Alpers were more severe than those associated with PEO, which agrees with the in vitro studies that suggest that the biochemical defects correlate with the severity and age of onset found in patients (Chan and Copeland 2009).

\section{POLG LINKER REGION IS IMPORTANT FOR BINDING TO THE ACCESSORY SUBUNIT}

The linker (also called spacer) region is between the polymerase and exonuclease domain and was named prior to biochemical characterizations of pol $\gamma$ that determined its functions. Structural studies identified critical contacts between the catalytic subunit of the holoenzyme and the homodimeric accessory subunit (encoded by $P O L G 2$ ) that are required for processivity (Lee et al. 2009). In particular, Glu540 and a helix comprised of amino acids 540 -558 are crucial to holoenzyme assembly (Lee et al. 2009; Lee et al. 2010a). Ala467 is also important for subunit interaction, and substitution to threonine (A467T) is a common POLG disease mutation. Not only is the A467T mutant enzyme compromised for its interaction with the accessory subunit, it also retains only $4 \%$ polymerase activity compared to WTenzyme (Chan et al. 2005a).

The A467T mutation is estimated to occur in $36 \%$ of all alleles associated with $P O L G$ disease. (Ferrari et al. 2005; Horvath et al. 2006; Nguyen et al. 2006; de Vries et al. 2007; Wong et al. 2008). In the general population, the frequency of the A467T mutation has been found to exist in between $0.2 \%$ to $1 \%$ of asymptomatic European populations (Van Goethem et al. 2001; Luoma et al. 2005; Winterthun et al. 2005; Horvath et al. 2006). Ataxic patients who are homozygous for the A467T mutation present with symptoms in their early to late teens (Van Goethem et al. 2004; Winterthun et al. 2005; Tzoulis et al. 2006); however, patients have often been reported to be compound heterozygous with A467T and at least one other POLG disease-associated mutation. Because of the severity of the A467T mutation on processivity and catalysis (Chan et al. 2005a), it is assumed that the other mutation determines the disease progression. For instance, Naviaux et al. (1999) reported an Alpers patient with reduced electron transport chain function, dicarboxylic aciduria, fulminant hepatic failure, refractory epilepsy, and lactic acidosis, which resulted in death at 42 months. Analysis of mtDNA and pol $\gamma$ activity from skeletal muscle biopsy indicated a reduction of mitochondrial DNA content to $30 \%$ of wild-type 
levels and no detectable pol $\gamma$ activity (Naviaux et al. 1999). Later sequencing of the POLG gene revealed compound heterozygosity with an A467T substitution in trans with a G to T nonsense mutation that converts Glu873 (GAG) to a stop codon (Naviaux and Nguyen 2004). POLG mRNAs containing the Glu873 nonsense mutation are degraded from the pool of mRNAs by nonsense mediated decay resulting in mono-allelic expression of POLG containing only the A467T mutation (Chan et al. 2005b).

Other examples of clinical presentations of compound heterozygotes include SANDO patients with A467T in one POLG allele and either R3P, L304R, or R627W in the other (Van Goethem et al. 2003a). One patient with ataxia-myopathy syndrome was shown to have A467T in one POLG allele and R627Q mutation in cis with the Q1236H single nucleotide polymorphism in the other POLG allele (Luoma et al. 2005). Other patients with ataxia were found to be heterozygous with the A467T mutation on one allele and W748S in cis with the E1143G mutation in the other allele (Van Goethem et al. 2004).

Very little is known about other linker domain mutations. Information about one linker domain mutation has demonstrated the difficulty of assigning disease causation to mutations, despite biochemical assays, structural data, and model systems. The G517V substitution was identified in simple and compound heterozygotes in many different disease presentations including Leigh syndrome, neuropathy, myopathy, sideroblastic anemia, and Kearns Sayre syndrome (Sarzi et al. 2007; Wong et al. 2008). However, the G517V substitution in recombinant pol $\gamma$ exhibits no major changes in catalysis, DNA binding, or binding to the accessory subunit (Kasiviswanathan and Copeland 2011). There are several possibilities to explain the contradiction between the association to mitochondrial disease and the biochemical data. It is possible that other pol $\gamma$ activities that are not routinely assayed, such as dRP lyase activity, are important for mtDNA replication. Alternatively, the assays may require a less minimalistic replisome and substrate to dissect the difference in activity between the enzymes, suggesting the need for proper reconstitution of mtDNA replication in vitro. More importantly, it is clear that the preponderance of evidence of association between a particular mutation and disease is neither sufficient nor a logical argument to propose a causal relationship. In the absence of genetic or biochemical data, the proper characterization of disease-associated mutations requires adequate genotypic and clinical family history.

\section{POL $\gamma$ EXONUCLEASE ACTIVITY, DISEASE, AND MTDNA MUTAGENESIS}

Identification of mutations associated with mitochondrial disease in the exonuclease domain resulted in an obvious and reasonable hypothesis: exonuclease domain mutations reduce the proofreading function of pol $\gamma$, resulting in an mtDNA mutator phenotype and ultimately leading to mitochondrial dysfunction and disease. Because specific mtDNA mutations at high enough cellular concentrations (or heteroplasmy) cause maternally inherited mitochondrial disease, general mtDNA mutagenesis caused by decreased proofreading activity could be a possible contributor to human disease.

Surprisingly, mutations that have been studied in the exonuclease domain, which are most conserved from humans to yeast, have not caused increases in mutagenesis in vivo or decreases in exonuclease activity in vitro (Baruffini et al. 2006; Stumpf et al. 2010; Szczepanowska and Foury 2010). In fact, kinetic data showed that disease-associated mutations increase exonuclease activity for both correct and mismatched primer-template termini (Lee et al. 2010b; Szczepanowska and Foury 2010). Because not all disease-associated mutations have been assayed for exonuclease activity, it is still possible that lack of proofreading can cause POLG-related diseases. However, proofreading activity may not factor into diseases that clinicians identify with POLG mutations. It is unknown if exonuclease-deficient pol $\gamma$ variants are found in the unaffected population, or in people affected by noncanonical POLG-associated diseases. It is also formally possible that mutations that eliminate exonuclease function of pol $\gamma$ are embryonic lethal. This seems un- 
likely considering that mice with exonucleasedeficient pol $\gamma$ are viable (Trifunovic et al. 2004; Kujoth et al. 2005), and exonuclease-deficient pol $\gamma$ efficiently replicates DNA in vitro.

To test the potential effects of eliminating mitochondrial proofreading function on disease, several groups used mouse models that disrupted pol $\gamma$ exonuclease activity. In the first mouse model that eliminated pol $\gamma$ exonuclease activity, the pol $\gamma$ variant was transgenically targeted to the heart, resulting in severe cardiomyopathy accompanied by mtDNA mutations and deletions (Zhang et al. 2000). Several years later, two independent groups created mice homozygous for mutations that disrupted exonuclease function (Trifunovic et al. 2004; Kujoth et al. 2005). These mice exhibited premature aging between 6 and 9 months, characterized by graying hair, loss of hair and hearing, curvature of the spine, enlarged hearts, and decreased body weight and bone density (Trifunovic et al. 2004; Kujoth et al. 2005). These observations have not only shown that exonuclease-deficient pol $\gamma$ does not cause embryonic lethality, but also have created discussion about the role of mtDNA mutations in aging and mitochondrial disease.

The degree of increase of mtDNA mutagenesis in POLG exonuclease-deficient mice was originally unclear. The increase in mtDNA mutagenesis reported in the mutants (three- to eightfold) is similar to the accumulation of mutations detected in 2- to 3-year-old mice (threeto 11-fold) (Trifunovic et al. 2004, 2005; Kujoth et al. 2005; Vermulst et al. 2007). However, mutation frequencies in young, wild-type mice is at or below the limit of detection using the method of PCR cloning and sequencing, which introduces mutations at $1.3 \times 10^{-4}$ mutations per base pair (Kujoth et al. 2005). This limitation was alleviated by an alternative method of quantifying mutation frequencies called the "random capture method," where the frequency of mutations that cause resistance to restriction endonuclease digestion is enriched, allowing more accurate estimations of mutation frequency $\left(7.1 \times 10^{-7}\right.$ mutations per base pair in wildtype mice and $1.6 \times 10^{-4}$ mutations per base pair in young heterozygotes) (Vermulst et al.
2007). Mutation frequency in homozygous mutant mice was confirmed using next-generation sequencing technology (Williams et al. 2010). The mutation frequency of heterozygotes, which were asymptomatic, was much higher than aged wild-type mice $\left(5.4 \times 10^{-6}\right.$ mutations per base pair) (Vermulst et al. 2007). Therefore, the increase in mutation frequency that occurs in older mice is not sufficient to cause phenotypes associated with aging. However, it is still possible that the extremely high mutation rate that occurs in homozygous POLG exonuclease-deficient mice is sufficient to cause or expedite the aging process. Both the relationship of mtDNA mutagenesis to disease and causes of increased mutagenesis are critical topics that need further exploration.

In addition to detecting point mutations, the random capture assay detected a 90 -fold increase in mtDNA deletions in homozygous POLG exonuclease-deficient mice as compared to age-matched wild-type or heterozygotes (Vermulst et al. 2008). While mtDNA deletions in wild-type and heterozygotes mostly occur among direct repeats of six or more nucleotides, mtDNA deletions in homozygous mutants occur independently of direct repeats (Vermulst et al. 2008). The mechanism for deletions between direct repeats is often attributed to strand-slippage, where a mispriming event occurs downstream of the correct target, a process that appears to be prevented by the proofreading exonuclease function of a polymerase. Interestingly, the lack of increase of deletions in the heterozygote suggests that the wild-type pol $\gamma$ protects against deletions that are caused by the exonuclease-deficient variant, suggesting an interplay between separate domains of both enzymes similar to the idea of extrinsic proofreading (Nick McElhinny et al. 2006). The role of mtDNA deletions in aging is controversial because there is disagreement about the absolute number of mtDNA deletions in the mitochondria. Because the random capture assay only detects relative numbers of deletions among various samples, deletion quantification has depended on Southern blots and long-range PCR techniques that are helpful when the majority of molecules have a particular deletion (Edgar et al. 
2009), but not when the size and distribution of deletions are expected to be random (Vermulst et al. 2009). Next-generation sequencing techniques detected the presence of deletions or tandem duplications only in the control region (the technique cannot distinguish between the two) in homozygous mutant mice (Williams et al. 2010). Other studies have found relatively abundant levels of linear nonreplicating molecules with large mtDNA deletions, probably because of pausing at the control and OriL regions during mtDNA replication (Bailey et al. 2009b; Ameur et al. 2011). However, amplification of large sections of single mtDNA molecules extracted from 2- to 3-year-old mice showed that only $0.07 \%-0.2 \%$ of molecules contained mtDNA deletions, arguing against the model that mtDNA deletions drive normal aging (Guo et al.2010). Similar to the story of mtDNA mutations, mtDNA deletions may not contribute to normal aging, and their role in premature aging in mice with exonuclease-deficient pol $\gamma$ is still unclear.

An important point that has confounded the study of mtDNA mutagenesis is the complicated measurement of mtDNA mutation rates, which in nuclear DNA studies are expressed as mutations per base pair per genome sequenced. To know the number of genomes sequenced, many approximations need to be made about the number and rate of genome replications per cell and mitochondrion, the rate of mitophagy (the targeted destruction of mitochondria) per cell, the number of mtDNA genomes that are destroyed during each mitophagy event, and whether mitophagy occurs more frequently with mutant genomes. These variables make all of the previous mutation frequencies difficult to interpret. For instance, if mtDNA deletions are preferentially biased for mitophagy, then the absolute number of deleted mtDNA molecules may underrepresent the true number of deletion events. Also, if mutant mtDNA tend to segregate and be amplified in particular cells, then mutant frequency may not reflect the number of cells with suboptimal ATP production. Mutation frequencies are normally determined in a population of cells; however, determining the mtDNA dynamics of a mutation requires measurements of individual cells. For instance, in heterozygous POLG exonuclease-deficient 15-month-old mice, $20 \%$ of cells in the duodenum were respiratory deficient as visualized by staining for loss of cytochrome oxidase (COX) activity (Vermulst et al. 2008). Even though the vast majority of mtDNA molecules contained a point mutation in these cells (but not deletions), the heterozygotes were asymptomatic presumably because there were enough cells with mitochondrial function. In the prematurely aging homozygous mutants, there were much higher percentages of COX-negative cells in the brain, liver, and duodenum (Vermulst et al. 2008). It is still undetermined whether the COX-negative cells in the homozygous mutants contain mostly mtDNA mutations or deletions, a finding that should resolve the controversy.

\section{GENETIC AND ENVIRONMENTAL EFFECTORS OF MITOCHONDRIAL DYSFUNCTION: SUGGESTIONS FOR THERAPEUTIC APPROACHES?}

Unfortunately, treatment of $P O L G$-related diseases has been limited to symptom management and supportive care. The predominance of liver involvement in the younger child has led to liver transplantation in some patients, but the outcome has been poor and is not recommended for POLG-related disease because of neurological involvement (Tzoulis et al. 2006; Wong et al. 2008). Even though seizures in $P O L G$ patients can be resistant to anti-seizure medications, the use of valproic acid should be avoided, because of induction of liver failure (Horvath et al. 2006; Tzoulis et al. 2006; Chinnery and Zeviani 2008). With a paucity of options known to treat $P O L G$-related mitochondrial diseases, it is important to use basic research to understand genetic and environmental changes that can suppress the molecular phenotype related to $P O L G$ mutations.

Targeting Oxidative Stress for Treatment of POLG-Related Disease

Therapies that target oxidative stress caused by dysfunctional mitochondria show promise. 
Recently, an early open-label study has suggested that a novel drug, $\alpha$-tocotrienol quinone (ATQ3), may have therapeutic value in treating mitochondrial disease (Shrader et al. 2011). This drug is a strong antioxidant, which is hypothesized to block free radicals and thereby prevent oxidative injury. While this medication is currently making its way through the clinical trial pathway, the true therapeutic value needs to be validated.

Studies using basic model systems may help understand the potential effectiveness of antioxidant therapy. A yeast study with homologous disease-associated mutations in the mitochondrial polymerase showed that high frequencies of mitochondrial dysfunction could be suppressed by treatment with the antioxidants $\mathrm{Mi}$ toQ and dihydrolipoic acid (Baruffini et al. 2006, 2011). However, the effect was specific to certain mutations for reasons that still need to be explored. In addition, the transgenic mouse model with the Y955C POLG allele targeted to the heart developed cardiomyopathy, loss of mtDNA, enlarged heart, and increased levels of 8-oxo-dG in its mtDNA, suggesting a role for oxidative damage in disrupting mtDNA replication and a benefit from antioxidant therapy (Lewis et al. 2007). Further support for the potential of antioxidant therapy is demonstrated by the attenuation of age-dependent cardiomyopathy in mice with mutations that inactivate pol $\gamma$ exonuclease function by overexpression of catalase, which reduces oxidative damage (Dai et al. 2010).

\section{Availability of Nucleotides Modifies Mitochondrial Dysfunction}

Mitochondrial toxicity is a common and dangerous side effect of HIV patients treated with nucleotide reverse transcription inhibitors (NRTIs). While the NRTIs were designed to inhibit HIV reverse transcriptase and not cellular polymerases, NRTI incorporation inhibits pol $\gamma$ replication (Kakuda 2000), and may cause mitochondrial toxicity in some cases. In support of this hypothesis, a POLG disease-associated mutation changing Arg964 to cysteine (R964C) was suggested to facilitate stavudine-induced toxicity (Yamanaka et al. 2007). Biochemical characterization of the $\mathrm{R} 964 \mathrm{C}$ variant demonstrated a threefold decrease in discrimination against stavudine (Bailey et al. 2009a). A yeast system that allowed stavudine uptake showed a very mild increase in frequency of mitochondrial dysfunction in the R964C yeast homolog (Baruffini and Lodi 2010). More advanced experimental models will be required to determine whether this decrease in stavudine discrimination is sufficient to cause mitochondrial toxicity.

Nucleotide concentrations may be crucial in proper mtDNA replication as evidenced by the disease-associated mutations in the small subunit of ribonucleotide reductase that catalyzes the limiting step of dNTP production (Bourdon et al.2007). Several disease-associated mutations show reduced binding affinities for nucleotides and would be sensitive to low nucleotide concentrations. One such example is the H932Y variant, which is able to incorporate nucleotides at near normal rates when the nucleotide concentration is raised 100-fold over the concentration needed for the wild-type enzyme (Stumpf et al. 2010). The increased frequency of mitochondrial dysfunction by the homologous mutation in yeast is suppressed by overexpressing ribonucleotide reductase, which increases nucleotide concentration (Stumpf et al. 2010). The suppression of disease-associated mutations by ribonucleotide reductase overexpression occurs for other nucleotide-binding defective mutants (Lecrenier and Foury 1995; Baruffini et al. 2006), suggesting a mechanism that could be targeted for mitochondrial therapies.

\section{Exercise Attenuates Premature Aging in POLG Mutant Mice}

A recent provocative study showed that premature aging in the POLG exonuclease-deficient mice can be at least delayed for several months by endurance exercise (Safdar et al. 2011). Not only are the mice that undergo exercise endurance phenotypically indistinguishable from wild-type, they also have similar frequency of mutant mtDNA and COX activity as wildtype. Interestingly, they exhibit about $50 \%$ higher mtDNA copy number. However, the mechanism for attenuating premature aging is unclear. It has been suggested that exercise promotes 
mitochondrial biogenesis via PGC- $1 \alpha$ facilitating a process that either dilutes mutant mtDNA or targets dysfunctional mtDNA for destruction (Safdar et al. 2011). According to this model, mitochondrial dynamics caused by fusion and fission is sufficient to offset the mutation load that is created by the lack of exonuclease activity. It is interesting to note that endurance exercise can only be undertaken by a fully developed mouse after many mitochondrial divisions and presumably the majority of mtDNA mutations have occurred. This suggests that the suppressive effects of endurance exercise may occur even if training starts later in life. Also, it would be interesting to know how temporary the effect of endurance training is on the accumulation of mtDNA mutations. This work should inspire future studies on the therapeutic effects of exercise for POLG-related diseases.

\section{CONCLUSIONS}

From the initial discovery of the first $P O L G$ disease-associated mutation a decade ago, research on POLG and mtDNA replication has spawned a wealth of information. Clinical reports have vastly improved and broadened the diagnoses and documented the mutations in many POLG-related diseases. The search for the polymerase defects in disease-associated mutants has resulted in the biochemical, genetic, and crystallographic dissection of the important activities of the polymerase. The development of the mitochondrial "mutator" mouse has inspired many labs to understand the role of mitochondrial mutations in pathology. Finally, the use of these tools allows more mechanistic approaches to therapeutic strategies. These developments in conjunction with new technology will hopefully provide new research tools that are needed to fully understand some of the mysteries of POLG-related diseases. For instance, improved sequencing technologies will allow broader studies of the entire spectrum of mutations in nuclear genes that affect mtDNA replication in disease patients. Also, reconstitution of mtDNA replication from tissue extracts and recombinant proteins will provide improved methods for determining mutations and envi- ronmental toxicants that cause mtDNA depletion. The better understanding of mtDNA dynamics will help determine how cells deal with mtDNA depletion and mutagenesis during the course of the disease. Finally, appropriate model systems will be developed to understand tissue specificity in mitochondrial diseases. This information will be crucial for improving both diagnosis and treatment of $P O L G$-related diseases.

\section{ACKNOWLEDGMENTS}

We and the rest of the POLG field are indebted to the hard work of Margaret Humble for maintaining and updating the pol $\gamma$ mutation database (http://tools.niehs.nih.gov/polg). We also thank Drs. Richard Gradman and Tammy Collins for comments and suggestions from their critical reading of this manuscript. This work is supported by the Intramural Research Program of the National Institutes of Health, the National Institute of Environmental Health Sciences (ES 065078), and the Mitochondrial Research Guild at Seattle Children's Hospital.

\section{REFERENCES}

Aitken H, Gorman G, McFarland R, Roberts M, Taylor RW, Turnbull DM. 2009. Clinical reasoning: Blurred vision and dancing feet: Restless legs syndrome presenting in mitochondrial disease. Neurology 72: e86-90.

Ameur A, Stewart JB, Freyer C, Hagstrom E, Ingman M, Larsson NG, Gyllensten U. 2011. Ultra-deep sequencing of mouse mitochondrial DNA: mutational patterns and their origins. PLoS Genet 7: e1002028.

Bailey CM, Kasiviswanathan R, Copeland WC, Anderson KS. 2009a. R964C mutation of DNA polymerase $\gamma$ imparts increased stavudine toxicity by decreasing nucleoside analog discrimination and impairing polymerase activity. Antimicrob Agents Chemother 53: 2610-2612.

Bailey LJ, Cluett TJ, Reyes A, Prolla TA, Poulton J, Leeuwenburgh C, Holt IJ. 2009b. Mice expressing an errorprone DNA polymerase in mitochondria display elevated replication pausing and chromosomal breakage at fragile sites of mitochondrial DNA. Nucleic Acids Res 37: 23272335.

Baruffini E, Lodi T. 2010. Construction and validation of a yeast model system for studying in vivo the susceptibility to nucleoside analogues of DNA polymerase $\gamma$ allelic variants. Mitochondrion 10: 183-187.

Baruffini E, Lodi T, Dallabona C, Puglisi A, Zeviani M, Ferrero I. 2006. Genetic and chemical rescue of the Saccharomyces cerevisiae phenotype induced by mitochondrial DNA polymerase mutations associated with 
progressive external ophthalmoplegia in humans. Hum Mol Genet 15: 2846-2855.

Baruffini E, Ferrero I, Foury F. 2007. Mitochondrial DNA defects in Saccharomyces cerevisiae caused by functional interactions between DNA polymerase $\gamma$ mutations associated with disease in human. Biochim Biophys Acto 1772: $1225-1235$.

Baruffini E, Horvath R, Dallabona C, Czermin B, Lamantea E, Bindoff L, Invernizzi F, Ferrero I, Zeviani M, Lodi T. 2011. Predicting the contribution of novel POLG mutations to human disease through analysis in yeast model. Mitochondrion 11: 182-190.

Bicknese AR, May W, Hickey WF, Dodson WE. 1992. Early childhood hepatocerebral degeneration misdiagnosed as valproate hepatotoxicity. Ann Neurol 32: 767-775.

Blok MJ, Van den Bosch BJ, Jongen E, Hendrickx A, de DieSmulders CE, Hoogendijk JE, Brusse E, de Visser M, PollThe BT, Bierau J, et al. 2009. The unfolding clinical spectrum of POLG mutations. J Med Genet 46: 776-785.

Bourdon A, Minai L, Serre V, Jais JP, Sarzi E, Aubert S, Chretien D, de Lonlay P, Paquis-Flucklinger V, Arakawa H, et al. 2007. Mutation of RRM2B, encoding p53-controlled ribonucleotide reductase ( $\mathrm{p} 53 \mathrm{R} 2$ ), causes severe mitochondrial DNA depletion. Nat Genet 39: 776-780.

Chan SS, Copeland WC. 2009. DNA polymerase $\gamma$ and mitochondrial disease: Understanding the consequence of POLG mutations. Biochim Biophys Acta 1787: 312-319.

Chan SSL, Longley MJ, Copeland WC. 2005a. The common A467T mutation in the human mitochondrial DNA polymerase $(P O L G)$ compromises catalytic efficiency and interaction with the accessory subunit. J Biol Chem 280: 31341-31346.

Chan SSL, Longley MJ, Naviaux RK, Copeland WC. 2005b. Mono-allelic POLG expression resulting from nonsensemediated decay and alternative splicing in a patient with Alpers syndrome. DNA Repair 4: 1381-1389.

Chan SSL, Longley MJ, Copeland WC. 2006. Modulation of the W748S mutation in DNA polymerase $\gamma$ by the E1143G polymorphism in mitochondrial disorders. Hum Mol Genet 15: 3473-3483.

Chinnery PF, Zeviani M. 2008. 155th ENMC workshop: Polymerase $\gamma$ and disorders of mitochondrial DNA synthesis, 21-23 September 2007, Naarden, The Netherlands. Neuromuscul Disord 18: 259-267.

Cohen BH, Naviaux RK. 2010. The clinical diagnosis of $P O L G$ disease and other mitochondrial DNA depletion disorders. Methods 51: 364-373.

Cohen BH, Chinnery PF, Copeland WC. 2010. POLG-related disorders. In Gene reviews at gene tests: Medical genetics information resource (http://wwwgenetestsorg), University of Washington, Seattle, WA.

Copeland WC. 2008. Inherited mitochondrial diseases of DNA replication. Annu Rev Med 59: 131-146.

Dai DF, Chen T, Wanagat J, Laflamme M, Marcinek DJ, Emond MJ, Ngo CP, Prolla TA, Rabinovitch PS. 2010. Age-dependent cardiomyopathy in mitochondrial mutator mice is attenuated by overexpression of catalase targeted to mitochondria. Aging Cell 9: 536-544.

de Vries MC, Rodenburg RJ, Morava E, van Kaauwen EP, Ter Laak H, Mullaart RA, Snoeck IN, van Hasselt PM, Harding P, van den Heuvel LP, et al. 2007. Multiple oxi- dative phosphorylation deficiencies in severe childhood multi-system disorders due to polymerase $\gamma$ (POLG1) mutations. Eur J Pediatr 166: 229-234.

Di Fonzo A, Bordoni A, Crimi M, Sara G, Bo RD, Bresolin N, Comi GP. 2003. POLG mutations in sporadic mitochondrial disorders with multiple mtDNA deletions. Hum Mutat 22: 498-499.

Dimmock D, Tang LY, Schmitt ES, Wong LJ. 2010. Quantitative evaluation of the mitochondrial DNA depletion syndrome. Clin Chem 56: 1119-1127.

Edgar D, Shabalina I, Camara Y, Wredenberg A, Calvaruso MA, Nijtmans L, Nedergaard J, Cannon B, Larsson NG, Trifunovic A. 2009. Random point mutations with major effects on protein-coding genes are the driving force behind premature aging in mtDNA mutator mice. Cell Metab 10: 131-138.

Engelsen BA, Tzoulis C, Karlsen B, Lillebo A, Laegreid LM, Aasly J, Zeviani M, Bindoff LA. 2008. POLG1 mutations cause a syndromic epilepsy with occipital lobe predilection. Brain 131: 818-828.

Fadic R, Russell JA, Vedanarayanan VV, Lehar M, Kuncl RW, Johns DR. 1997. Sensory ataxic neuropathy as the presenting feature of a novel mitochondrial disease. Neurology 49: 239-245.

Ferrari G, Lamantea E, Donati A, Filosto M, Briem E, Carrara F, Parini R, Simonati A, Santer R, Zeviani M. 2005. Infantile hepatocerebral syndromes associated with mutations in the mitochondrial DNA polymerase- $\gamma \mathrm{A}$. Brain 128: 723-731.

Gonzalez-Vioque E, Blazquez A, Fernandez-Moreira D, Bornstein B, Bautista J, Arpa J, Navarro C, Campos Y, Fernandez-Moreno MA, Garesse R, et al. 2006. Association of novel POLG mutations and multiple mitochondrial DNA deletions with variable clinical phenotypes in a Spanish population. Arch Neurol 63: 107-111.

Gray H, Wong TW. 1992. Purification and identification of subunit structure of the human mitochondrial DNA polymerase. J Biol Chem 267: 5835-5841.

Graziewicz MA, Longley MJ, Bienstock RJ, Zeviani M, Copeland WC. 2004. Structure-function defects of human mitochondrial DNA polymerase in autosomal dominant progressive external ophthalmoplegia. Nat Struct Mol Biol 11: 770-776.

Guo X, Kudryavtseva E, Bodyak N, Nicholas A, Dombrovsky I, Yang D, Kraytsberg Y, Simon DK, Khrapko K. 2010. Mitochondrial DNA deletions in mice in men: Substantia nigra is much less affected in the mouse. Biochim Biophys Acta 1797: 1159-1162.

Haas RH, Parikh S, Falk MJ, Saneto RP, Wolf NI, Darin N, Cohen BH. 2007. Mitochondrial disease: A practical approach for primary care physicians. Pediatrics 120: $1326-1333$.

Haas RH, Parikh S, Falk MJ, Saneto RP, Wolf NI, Darin N, Wong LJ, Cohen BH, Naviaux RK. 2008. The in-depth evaluation of suspected mitochondrial disease. Mol Genet Metab 94: 16-37.

Hakonen AH, Heiskanen S, Juvonen V, Lappalainen I, Luoma PT, Rantamaki M, Goethem GV, Lofgren A, Hackman P, Paetau A, et al. 2005. Mitochondrial DNA polymerase W748S mutation: A common cause of autosomal recessive ataxia with ancient European origin. Am J Hum Genet 77: 430-441. 
J.D. Stumpf et al.

Hance N, Ekstrand MI, Trifunovic A. 2005. Mitochondrial DNA polymerase $\gamma$ is essential for mammalian embryogenesis. Hum Mol Genet 14: 1775-1783.

Harding BN. 1990. Progressive neuronal degeneration of childhood with liver disease (Alpers-Huttenlocher syndrome): A personal review. J Child Neurol 5: 273-287.

Hirano M, Silvestri G, Blake DM, Lombes A, Minetti C, Bonilla E, Hays AP, Lovelace RE, Butler I, Bertorini TE, et al. 1994. Mitochondrial neurogastrointestinal encephalomyopathy (MNGIE): Clinical, biochemical, and genetic features of an autosomal recessive mitochondrial disorder. Neurology 44: 721-727.

Horvath R, Hudson G, Ferrari G, Futterer N, Ahola S, Lamantea E, Prokisch H, Lochmuller H, McFarland R, Ramesh V, et al. 2006. Phenotypic spectrum associated with mutations of the mitochondrial polymerase $\gamma$ gene. Brain 129: 1674-1684.

Kakuda TN. 2000. Pharmacology of nucleoside and nucleotide reverse transcriptase inhibitor-induced mitochondrial toxicity. Clin Ther 22: 685-708.

Kasiviswanathan R, Copeland WC. 2011. Biochemical analysis of the G517V POLG variant reveals wild-type like activity. Mitochondrion 11: 929-934.

Kasiviswanathan R, Longley MJ, Chan SS, Copeland WC. 2009. Disease mutations in the human mitochondrial DNA polymerase thumb subdomain impart severe defects in MtDNA replication. J Biol Chem 284: 19501-19510.

Kujoth GC, Hiona A, Pugh TD, Someya S, Panzer K, Wohlgemuth SE, Hofer T, Seo AY, Sullivan R, Jobling WA, et al. 2005. Mitochondrial DNA mutations, oxidative stress, and apoptosis in mammalian aging. Science 309: 481-484.

Lamantea E, Tiranti V, Bordoni A, Toscano A, Bono F, Servidei S, Papadimitriou A, Spelbrink H, Silvestri L, Casari G, et al. 2002. Mutations of mitochondrial DNA polymerase $\gamma$ are a frequent cause of autosomal dominant or recessive progressive external ophthalmoplegia. Ann Neurol 52: 211-219.

Lecrenier N, Foury F. 1995. Overexpression of the RNR1 gene rescues Saccharomyces cerevisiae mutants in the mitochondrial DNA polymerase-encoding MIP1 gene. Mol Gen Genet 249: 1-7.

Lee YS, Kennedy WD, Yin YW. 2009. Structural insight into processive human mitochondrial DNA synthesis and disease-related polymerase mutations. Cell 139: 312-324.

Lee YS, Lee S, Demeler B, Molineux IJ, Johnson KA, Yin YW. 2010a. Each monomer of the dimeric accessory protein for human mitochondrial DNA polymerase has a distinct role in conferring processivity. J Biol Chem 285: 1490-1499.

Lee YS, Molineux IJ, Yin YW. 2010b. A single mutation in human mitochondrial DNA polymerase pol $\gamma \mathrm{A}$ affects both polymerization and proofreading activities, but only as a holoenzyme. J Biol Chem 285: 28105-28116.

Lewis W, Day BJ, Kohler JJ, Hosseini SH, Chan SSL, Green E, Haase CP, Keebaugh E, Long R, Ludaway T, et al. 2007. MtDNA depletion, oxidative stress, cardiomyopathy, and death from transgenic cardiac targeted human mutant polymerase $\gamma$. Lab Invest 87: 326-335.

Lim SE, Longley MJ, Copeland WC. 1999. The mitochondrial p55 accessory subunit of human DNA polymerase $\gamma$ enhances DNA binding, promotes processive DNA synthesis, and confers $N$-ethylmaleimide resistance. J Biol Chem 274: 38197-38203.
Longley MJ, Prasad R, Srivastava DK, Wilson SH, Copeland WC. 1998a. Identification of $5^{\prime}$-deoxyribose phosphate lyase activity in human DNA polymerase $\gamma$ and its role in mitochondrial base excision repair in vitro. Proc Natl Acad Sci 95: 12244-12248.

Longley MJ, Ropp PA, Lim SE, Copeland WC. 1998b. Characterization of the native and recombinant catalytic subunit of human DNA polymerase $\gamma$ : Identification of residues critical for exonuclease activity and dideoxynucleotide sensitivity. Biochemistry 37: 10529-10539.

Longley MJ, Graziewicz MA, Bienstock RJ, Copeland WC. 2005. Consequences of mutations in human DNA polymerase $\gamma$. Gene 354: 125-131.

Longley MJ, Humble MM, Sharief FS, Copeland WC. 2010. Disease variants of the human mitochondrial DNA helicase encoded by C10orf2 differentially alter protein stability, nucleotide hydrolysis and helicase activity. J Biol Chem 285: 29690-29702.

Luoma P, Melberg A, Rinne JO, Kaukonen JA, Nupponen NN, Chalmers RM, Oldfors PA, Rautakorpi I, Peltonen PL, Majamaa PK, et al. 2004. Parkinsonism, premature menopause, and mitochondrial DNA polymerase $\gamma$ mutations: Clinical and molecular genetic study. Lancet 364: 875-882.

Luoma PT, Luo N, Loscher WN, Farr CL, Horvath R, Wanschitz J, Kiechl S, Kaguni LS, Suomalainen A. 2005. Functional defects due to spacer-region mutations of human mitochondrial DNA polymerase in a family with an ataxia-myopathy syndrome. Hum Mol Genet 14: 19071920.

Milone M, Brunetti-Pierri N, Tang LY, Kumar N, Mezei MM, Josephs K, Powell S, Simpson E, Wong LJ. 2008. Sensory ataxic neuropathy with ophthalmoparesis caused by POLG mutations. Neuromuscul Disord 18: 626-632.

Naviaux RK, Nguyen KV. 2004. POLG Mutations associated with Alpers' syndrome and mitochondrial DNA depletion. Ann Neurol 55: 706-712.

Naviaux RK, Nyhan WL, Barshop BA, Poulton J, Markusic D, Karpinski NC, Haas RH. 1999. Mitochondrial DNA polymerase $\gamma$ deficiency and mtDNA depletion in a child with Alpers' syndrome. Ann Neurol 45: 54-58.

Nguyen KV, Sharief F, Chan SSL, Copeland WC, Naviaux RK. 2006. Molecular diagnosis of Alpers syndrome. J Hepatology 45: 108-116.

Nick McElhinny SA, Pavlov YI, Kunkel TA. 2006. Evidence for extrinsic exonucleolytic proofreading. Cell Cycle 5: $958-962$.

Pagnamenta AT, Taanman JW, Wilson CJ, Anderson NE, Marotta R, Duncan AJ, Bitner-Glindzicz M, Taylor RW, Laskowski A, Thorburn DR, et al. 2006. Dominant inheritance of premature ovarian failure associated with mutant mitochondrial DNA polymerase $\gamma$. Hum Reprod 21: 2467-2473.

Ponamarev MV, Longley MJ, Nguyen D, Kunkel TA, Copeland WC. 2002. Active site mutation in DNA polymerase $\gamma$ associated with progressive external ophthalmoplegia causes error-prone DNA synthesis. J Biol Chem 277: 15225-15228.

Safdar A, Bourgeois JM, Ogborn DI, Little JP, Hettinga BP, Akhtar M, Thompson JE, Melov S, Mocellin NJ, Kujoth GC, et al. 2011. Endurance exercise rescues progeroid aging and induces systemic mitochondrial rejuvenation 
in mtDNA mutator mice. Proc Natl Acad Sci 108: 4135 4140.

Saneto RP, Naviaux RK. 2010. Polymerase $\gamma$ disease through the ages. Dev Disabil Res Rev 16: 163-174.

Saneto RP, Lee IC, Koenig MK, Bao X, Weng SW, Naviaux RK, Wong LJ. 2010. POLG DNA testing as an emerging standard of care before instituting valproic acid therapy for pediatric seizure disorders. Seizure 19: 140-146.

Sarzi E, Bourdon A, Chretien D, Zarhrate M, Corcos J, Slama A, Cormier-Daire V, de Lonlay P, Munnich A, Rotig A. 2007. Mitochondrial DNA depletion is a prevalent cause of multiple respiratory chain deficiency in childhood. J Pediatr 150: 531-534, e531-e536.

Shrader WD, Amagata A, Barnes A, Enns GM, Hinman A, Jankowski O, Kheifets V, Komatsuzaki R, Lee E, Mollard P, et al. 2011. $\alpha$-Tocotrienol quinone modulates oxidative stress response and the biochemistry of aging. Bioorg Med Chem Lett 21: 3693-3698.

Stuart GR, Santos JH, Strand MK, Van Houten B, Copeland WC. 2006. Mitochondrial DNA defects in S. cerevi siae with mutations in DNA polymerase $\gamma$ associated with progressive external ophthalmolplegia. Hum Mol Genet 15: 363-374.

Stumpf JD, Copeland WC. 2011. Mitochondrial DNA replication and disease: Insights from DNA polymerase $\gamma$ mutations. Cell Mol Life Sci 68: 219-233.

Stumpf JD, Bailey CM, Spell D, Stillwagon M, Anderson KS, Copeland WC. 2010. mip1 Containing mutations associated with mitochondrial disease causes mutagenesis and depletion of mtDNA in Saccharomyces cerevisiae. Hum Mol Genet 19: 2123-2133.

Szczepanowska K, Foury F. 2010. A cluster of pathogenic mutations in the $3^{\prime}-5^{\prime}$ exonuclease domain of DNA polymerase $\gamma$ defines a novel module coupling DNA synthesis and degradation. Hum Mol Genet 19: 3516-3529.

Tang S, Wang J, Lee NC, Milone M, Halberg MC, Schmitt ES, Craigen WJ, Zhang W, Wong LJ. 2011. Mitochondrial DNA polymerase $\gamma$ mutations: An ever expanding molecular and clinical spectrum. J Med Genet 48: 669-681.

Trifunovic A, Wredenberg A, Falkenberg M, Spelbrink JN, Rovio AT, Bruder CE, Bohlooly YM, Gidlof S, Oldfors A, Wibom R, et al. 2004. Premature ageing in mice expressing defective mitochondrial DNA polymerase. Nature 429: 417-423.

Trifunovic A, Hansson A, Wredenberg A, Rovio AT, Dufour E, Khvorostov I, Spelbrink JN, Wibom R, Jacobs HT, Larsson NG. 2005. Somatic mtDNA mutations cause aging phenotypes without affecting reactive oxygen species production. Proc Natl Acad Sci 102: 17993-17998.

Tulinius MH, Hagne I. 1991. EEG findings in children and adolescents with mitochondrial encephalomyopathies: A study of 25 cases. Brain Dev 13: 167-173.

Tzoulis C, Engelsen BA, Telstad W, Aasly J, Zeviani M, Winterthun S, Ferrari G, Aarseth JH, Bindoff LA. 2006. The spectrum of clinical disease caused by the A467T and W748S POLG mutations: A study of 26 cases. Brain 129: $1685-1692$.

Uusimaa J, Hinttala R, Rantala H, Paivarinta M, Herva R, Roytta M, Soini H, Moilanen JS, Remes AM, Hassinen IE, et al. 2008. Homozygous W748S mutation in the POLG1 gene in patients with juvenile-onset Alpers syndrome and status epilepticus. Epilepsia 49: 1038-1045.
Van Goethem G, Dermaut B, Lofgren A, Martin JJ, Van Broeckhoven C. 2001. Mutation of POLG is associated with progressive external ophthalmoplegia characterized by mtDNA deletions. Nature Genet 28: 211-212.

Van Goethem G, Martin JJ, Dermaut B, Lofgren A, Wibail A, Ververken D, Tack P, Dehaene I, Van Zandijcke M, Moonen M, et al. 2003a. Recessive POLG mutations presenting with sensory and ataxic neuropathy in compound heterozygote patients with progressive external ophthalmoplegia. Neuromuscul Disord 13: 133-142.

Van Goethem G, Mercelis R, Lofgren A, Seneca S, Ceuterick C, Martin JJ, Van Broeckhoven C. 2003b. Patient homozygous for a recessive POLG mutation presents with features of MERRF. Neurology 61: 1811-1813.

Van Goethem G, Luoma P, Rantamaki M, Al Memar A, Kaakkola S, Hackman P, Krahe R, Lofgren A, Martin JJ, De Jonghe P, et al. 2004. POLG mutations in neurodegenerative disorders with ataxia but no muscle involvement. Neurology 63: 1251-1257.

Vermulst M, Bielas JH, Kujoth GC, Ladiges WC, Rabinovitch PS, Prolla TA, Loeb LA. 2007. Mitochondrial point mutations do not limit the natural lifespan of mice. Nature Genet 39: 540-543.

Vermulst M, Wanagat J, Kujoth GC, Bielas JH, Rabinovitch PS, Prolla TA, Loeb LA. 2008. DNA deletions and clonal mutations drive premature aging in mitochondrial mutator mice. Nature Genet 40: 392-394.

Vermulst M, Wanagat J, Loeb LA. 2009. On mitochondria, mutations, and methodology. Cell Metab 10: 437.

Walter MC, Czermin B, Muller-Ziermann S, Bulst S, Stewart JD, Hudson G, Schneiderat P, Abicht A, HolinskiFeder E, Lochmuller H, et al. 2010. Late-onset ptosis and myopathy in a patient with a heterozygous insertion in POLG2. J Neurol 257: 1517-1523.

Williams SL, Huang J, Edwards YJ, Ulloa RH, Dillon LM, Prolla TA, Vance JM, Moraes CT, Zuchner S. 2010. The mtDNA mutation spectrum of the progeroid Polg mutator mouse includes abundant control region multimers. Cell Metab 12: 675-682.

Winterthun S, Ferrari G, He L, Taylor RW, Zeviani M, Turnbull DM, Engelsen BA, Moen G, Bindoff LA. 2005 Autosomal recessive mitochondrial ataxic syndrome due to mitochondrial polymerase $\gamma$ mutations. Neurology 64 : 1204-1208.

Wolf NI, Rahman S, Schmitt B, Taanman JW, Duncan AJ, Harting I, Wohlrab G, Ebinger F, Rating D, Bast T. 2009. Status epilepticus in children with Alpers' disease caused by POLG1 mutations: EEG and MRI features. Epilepsia 50: 1596-1607.

Wong LJ, Naviaux RK, Brunetti-Pierri N, Zhang Q, Schmitt ES, Truong C, Milone M, Cohen BH, Wical B, Ganesh J, et al. 2008. Molecular and clinical genetics of mitochondrial diseases due to POLG mutations. Hum Mutat 29: E150-E172.

Yamanaka H, Gatanaga H, Kosalaraksa P, MatsuokaAizawa S, Takahashi T, Kimura S, Oka S. 2007. Novel mutation of human DNA polymerase $\gamma$ associated with mitochondrial toxicity induced by anti-HIV treatment. J Infect Dis 195: 1419-1425.

Zhang D, Mott JL, Chang SW, Denniger G, Feng Z, Zassenhaus HP. 2000. Construction of transgenic mice with tissue-specific acceleration of mitochondrial DNA mutagenesis. Genomics 69: 151-161. 